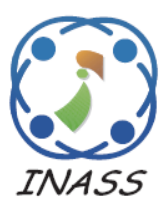

\title{
Lecturer-Course Assignment Model in National Joint Courses Program to Improve Education Quality and Lecturers' Time Preference
}

\author{
Purba Daru Kusuma ${ }^{1 *} \quad$ Dimas Adiputra ${ }^{2}$ \\ ${ }^{1}$ Computer Engineering, Telkom University, Indonesia \\ ${ }^{2}$ Electrical Engineering, Institut Teknologi Telkom Surabaya, Indonesia \\ * Corresponding author’s Email: purbodaru@telkomuniversity.ac.id
}

\begin{abstract}
One critical problem in Indonesia's national joint courses program, initiated by the ministry of education and culture of Indonesia, is the lecturer-course assignment problem. Although the lecturer-course assignment problem has been studied widely as part of the education timetabling problem, no existing lecturer-course assignment model suits this circumstance. The new cases in this program are as follows. First, this program is conducted online. Second, the participants are students and lecturers from different universities. Based on this problem, this work proposes a novel lecturer-course assignment model that suits this program. The lecturers' preferred courses and timeslots become hard constraints. The model has three objectives: (1) maximizing the educational quality, (2) maximizing the lecturers' time preference, and (3) minimizing the number of unserved classes. This model is developed by using integer linear programming and optimized by using cloud theory-based simulated annealing. This proposed model is then compared with the four previous lecturers-course assignment models. The first model concerns about minimizing the number of unserved classes, while the second model focuses on maximizing the education quality. The maximum number of classes per course for every lecturer is considered in the third model while balancing the lecturer's load (teach, research, community service) is the feature of the fourth model. The research concludes that the proposed model is appropriate for lecture-course assignment in Indonesia's national joint courses program compared to the previous models. Based on the simulation result, the proposed model performs moderately in education quality and several unserved classes. Meanwhile, the proposed model is the best in the timeslot preference aspect by creating a $25 \%$ to $28 \%$ higher total timeslot score than other previous models.
\end{abstract}

Keywords: Assignment problem, Lecturer, Courses, Simulated annealing, COVID-19.

\section{Introduction}

Two circumstances affected the higher education system in Indonesia in 2020. The first circumstance is the outbreak of the COVID-19 pandemic. This pandemic has reshaped people's behaviour in many aspects, especially in education. Due to the social distancing and lockdown policy [1], educational institutions and universities were forced to move from the traditional face-to-face approach to fully online learning [2]. Teachers and students are now familiar with several online collaboration platforms, such as Google Classroom, Zoom, and Microsoft Teams [3].
The second circumstance is the initiation of the national program Merdeka Belajar Kampus Merdeka (MBKM) by the Ministry of Education and Culture of Indonesia. Through this program, higher education students can take courses more independently, not only from their study program in their university, but they can also take classes from other study programs, other universities, or industries with certain credits. As the implementation, the ministry also initiated a national joint courses program so that students from various universities can take courses or be taught by lecturers from different universities. Google also started a similar program. This program was conducted online in the form of e-learning. It has advantages, which can be accessed widely, 
especially for students in rural and remote areas, which benefits e-learning [2]. E-learning also has another advantage in eliminating the school-home travel cost [4].

One problem in this national joint course program is the lecturer-course assignment problem. There are many elective courses in this program, lecturers capable of handling these courses, and students who can choose the provided courses. In a program conducted by Google, the lecturers stated some courses that they are capable of and some available timeslots. On the other side, there are certain numbers of classes with determined timeslots and courses.

However, there is no lecturer-course assignment model that suits to be implemented in this program directly even though the lecturer-course assignment problem has been widely studied as a part of the education timetabling problem [5]. The first reason is that previous studies assumed that the face-to-face approach is applied to need physical rooms $[6,7]$. Secondly, many lecturer-courses assignment studies were conducted in a small environment (i.e., study program, faculty, or university), where the relationship between the institution and its lecturers is authoritative, as reported by Ngo, Jaafar, Aziz, and Anh [8]. In this system, although lecturers can propose their preferred timeslots or days, in the end, they must follow a schedule determined by their institution [9]. Besides the timeslot, the institution also decides their lecturers' teaching load [10, 11]. In the national joint courses program, the mechanism for lecturers is voluntary so that the lecturers will teach courses only if they are in their preferences and on their preferred timeslots.

Based on this problem, a novel lecturer-course assignment model is proposed in this work. This model accommodates the lecturer's preferred courses and timeslots to suit the national joint courses program. This model has three objectives. The first objective is maximizing the educational quality by allocating the classes to the most competent lecturers. The second objective is maximizing the lecturers' satisfaction by giving a course to a possible preferred timeslot. The third objective minimizes the number of unserved classes rarely concerned in many previous lecturer-courses assignment problem studies.

Based on this explanation, the contributions of this work are as follows.

- This model accommodates the lecturers' preferred timeslots and lecturers' preferred courses as hard constraints rather than soft constraints like in many lecturers-courses assignment studies.
- The number of unserved classes is concerned as one of the model objectives.

This model is developed by using integer linear programming so that it consists of two parts: the objective and the constraints. Then, this model is optimized by using cloud theory-based simulated annealing (CTA). There are several reasons for adopting the CTA. First, metaheuristic methods were widely used in many education assignment problem studies, such as simulated annealing [12], genetic algorithm [8], branch-and-bound [13], tabu search [11], and so on. Second, simulated annealing is a metaheuristic method that focuses on achieving global optimization by avoiding the optimal local trap [14]. The cloud theory-based simulated annealing is an improved method of basic simulated annealing that provides better performance in achieving faster and better solutions using a population-based approach [15].

This paper is organized as follows. The background, research objective, contribution, and paper organization are described in the first section. The previous works related to the assignment problem and lecturer-course assignment problem are explored in the second section. The third section explains the proposed model, including the architecture and mathematical model. Then, the fourth section describes the simulation and the results. The findings are discussed in the fifth section. Finally, the sixth section concludes the work and proposes the future research potentials.

\section{Related works}

Assignment problem is a subject that has been studied widely. This study was conducted in many areas, such as sport, transportation, education and so on. [12]. In general, an assignment problem can be defined as a mechanism to assign jobs or tasks to a certain number of facilities [16]. An assignment problem can also be described as setting a certain number of objects to a certain number of other things in the optimal ways [12]. The common goal of the assignment problem is minimizing cost or maximizing profit [17]. The assignment problem can also be seen as a combinatorial optimization problem and part of operational research [18]. In the personnel assignment problem, each worker has different competencies to handle each task [19], so those tasks must be assigned to the possible competent worker.

The educational assignment problem can be divided into two issues: timetabling and allocation [12]. In the academic field, the assignment problem is how to allocate courses or tasks based on the 
Table 1. Latest studies in lecturers-courses assignment problem

\begin{tabular}{|c|l|l|l|l|}
\hline Author & \multicolumn{1}{|c|}{ Objectives } & Scope & \multicolumn{1}{|c|}{$\begin{array}{c}\text { Relation } \\
\text { Model }\end{array}$} & Method \\
\hline$[16]$ & $\begin{array}{l}\text { maximizing effectiveness } \\
\text { minimizing lecture preparation time }\end{array}$ & department & mandatory & $\begin{array}{l}\text { linear programming } \\
\text { Hungarian algorithm }\end{array}$ \\
\hline$[10]$ & $\begin{array}{l}\text { maximizing lecturer's capability } \\
\text { adjusting teaching load }\end{array}$ & university & mandatory & $\begin{array}{l}\text { linear programming } \\
\text { branch-and-bound algorithm }\end{array}$ \\
\hline$[8]$ & $\begin{array}{l}\text { maximizing lecturers' preference } \\
\text { (subject and timeslot) } \\
\text { minimizing mismatch between lecturer's } \\
\text { competence and subject }\end{array}$ & university & mandatory & genetic algorithm \\
\hline$[9]$ & $\begin{array}{l}\text { maximizing total competence score } \\
\text { malancing the teachers' load }\end{array}$ & department & mandatory & mixed integer programming \\
\hline$[13]$ & $\begin{array}{l}\text { minimizing the number of courses } \\
\text { without professors }\end{array}$ & university & mandatory & $\begin{array}{l}\text { simulated annealing } \\
\text { tabu search }\end{array}$ \\
\hline & $\begin{array}{l}\text { maximizing lecturers' time preference } \\
\text { maximizing lecturers' course preference } \\
\text { minimizing the number of unserved } \\
\text { classes }\end{array}$ & national & voluntary & $\begin{array}{l}\text { integer linear programming } \\
\text { branch-and-bound algorithm }\end{array}$ \\
\hline this work & annealing \\
\hline
\end{tabular}

faculties' competencies [9]. Besides, the teaching load [10] and schedule [9] are also concerned.

As an operational research study, there are several common constraints in the lecturer-course assignment problem. These constraints are as follows.

- There are the minimum and maximum teaching loads [9].

- The course is assigned to high competent faculty [9].

- The courses are conducted in determining time intervals [7].

- A lecturer can only handle a class in a one-time interval [7].

- A student cannot attend more than one lecture at one time [6].

The studies in lecturer-course assignment problems were conducted based on a specific objective and used certain methods as shown by several recent studies in Table 1. This work is also added in the last row, so that the comparison among models and the position of this work are clear. More detail explanation is described below.

The assignment model in [16] considered the lecturer's effectiveness related to the course. Firstly, the method measures the effectiveness score of every lecturer related to all provided courses. The effectiveness score depends on the lecturer's competency, quality, and experience. The measurement was then presented in a score matrix. Finally, optimization process was conducted by using Hungarian method.

Wicaksono and Wisesa [10] developed lecturers' assignment model based on the national higher education directorate policy. The main constraint is the lecturer must take 12 to 16 credits load. Here, the credits load included teaching, research, and community service. The lecturers were scored according to their expertise. Then, based on the constraint and lecturers score, the lectures-courses assignment was conducted by using linear programming.

The assignment model in [8] was a multi objective lecturers-courses assignment model. This work was conducted based on case in computing fundamental department at FPT University in Vietnam. The objectives were maximizing lecturers' courses preference, maximizing lecturers' time preference, minimizing the gap between the lecturer's number of assigned classes and the lecturer's preferred number of classes, and minimizing the lecturer's number of parts of the day. Besides as objectives, lecturer's preferred timeslots and courses also became the hard constraints. In this work, there was minimum number of classes that must be handled by every lecturer.

Ongy [9] proposed a lecturers-courses assignment model for a department scale. Its objective was to maximize the total competence score. The competence score was obtained based on the lecturer's competence to teach a course. There were several hard constraints. There were maximum number of classes and maximum number of classes per course for every lecturer. There were also minimum and maximum loads for every lecturer because the lecturer's obligation was not only teaching. For instance, some lectures are subjected to administrative position, thesis supervising, and other academic supporting role. 
Gunawan and Ng [11] developed a complex lecturers-courses assignment model, where the lecturers were grouped into full-time lecturers and part-time lecturers. In addition, a class could be handled by several lecturers but should not exceed the maximum number of lecturers for a class. Like [9] and [10], the lecturers' load was not teaching only. Therefore, the assignment model also has limitation in number of subjects for every lecturer to minimize the class preparation effort.

Arratia-Martinez, Maya-Padron, and AvilaTorres [13] also proposed lecturers-courses assignment problem with complex circumstance. The objective was to minimize the number of classes without professor [13] or unserved classes. In this model, the professor' courses preference became hard constraint. It means that a professor would not be assigned to a class beyond his competence. His courses preference was not ranked. These courses were treated equally so that there was not prioritization among these courses. The reason was when the model has the course preference as a hard constraint, then it will induce the possibility of unserved class.

Based on previous studies, the paper concludes that the lecturers-courses assignment problem mainly focused on two main objectives. The first objective is to allocate the courses to the most competent lecturer. The second objective is to ensure the compliance to the teaching load policy.

Many studies were conducted in a department or university scale, where the assignment result was mandatory for the lecturer. Although the lecturers have their courses and timeslots preference, they must follow the assignment result once it has been created. In many cases, the assignment result is less preferred by the lecturers in terms of course or timeslot.

Choosing inappropriate constraint can introduce new problem in the assignment model, such as the unserved class due to course preference constraint. Work by [8] assumed the timeslot and course preferences as hard constraints. However, the drawback has not been addressed well as it failed to explain the logical consequence in the possibility of the unserved classes due to the course preference. In other work by [13], the course preference is used as the hard constraint, but all courses within lecturer's preference were treated equally to avoid the unserved class issue.

Meanwhile, this research proposed a model that combines, simplifies, and modifies the models in [8] and [13]. The purpose of the model is to have assignment model that comply with the requirements of the voluntary based national joint courses program, where the timeslot and course preferences are the hard constraints. The assignment model is simpler because the national joint courses program does not have any limitation in the number of courses, load unit, number of classes, and so on due to its voluntary approach. Moreover, this proposed model improves the existing assignment model in national joint course program by adding prioritization within the courses and timeslots preferences.

\section{Model}

The joint-courses system consists of several entities: lecturers, courses, timeslots, classes, and timeslots. A lecturer is a person (faculty member) who have certain competence to deliver the courses. A course is a unit of teaching taught by a lecturer. The class is a set of students who take the same course, led by the same lecturer at the same timeslot. The number of members in a class is fixed, and it may vary among the classes. The members of a class are also set. A timeslot is a limited time window occupied by a class so that a course can be delivered within. There are a certain number of fixed timeslots within a week, and they are repeated weekly.

The relationship between courses and lecturers is many-to-many. A lecturer can handle a certain number of courses, and a certain number of lecturers can handle a course. This relationship is illustrated in Fig. 1. The list of the courses dealt with by a lecturer is ordered based on the lecturer's competence or preference in handling these courses. In Fig. 1, there are four courses and two lecturers. Both lecturers had three courses each. The first lecturer runs courses 1,2, and 4 and the second lecturer holds courses 2,3 , and 4 . In the formalized form, based on the preferred order, the set of courses that is handled by lecturer 1 is \{course 4 , course 1 , course 2 \}. It means course four is the most preferred, and course 2 is the least preferred for lecturer 1 .

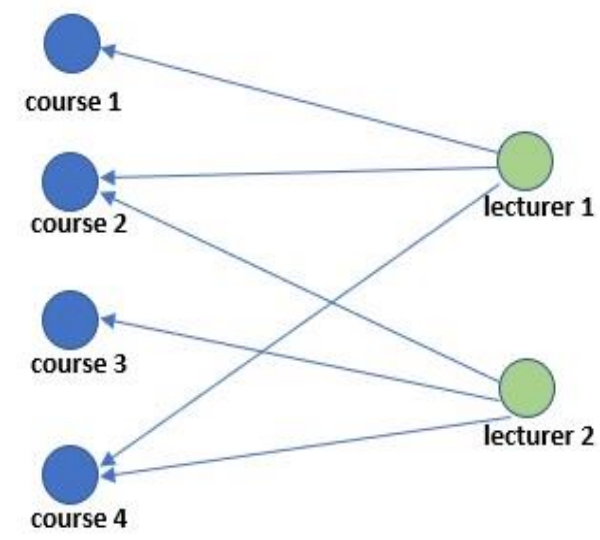

Figure. 1 Relationship between lecturers and courses 


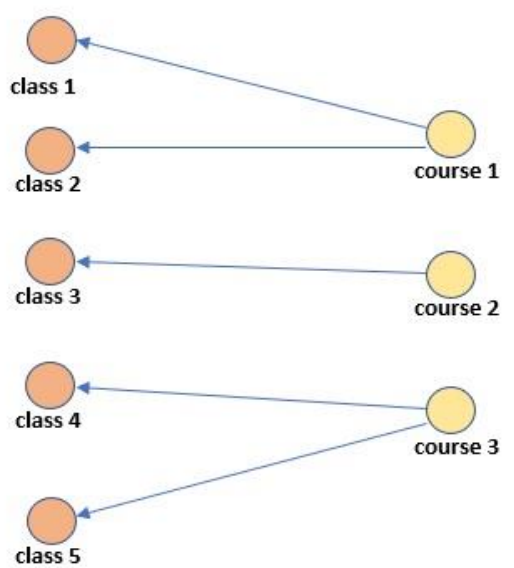

Figure. 2 Relationship between classes and courses

The relationship between the classes and courses is many-to-one. It means a class is for a single course only. Meanwhile, a course can be delivered in several classes. This relationship is illustrated in Fig. 2. In Fig. 2, there are five classes and three courses. Course 1 is delivered in class 1 and class 2 . Course 2 is delivered in class 3 . Course 3 is delivered in class 4 and class 5 .

There are several assumptions used in this model as follow.

- The number of classes is predetermined.

- The course delivered in each class is predetermined.

- The timeslot of each class is predetermined.

- The number of lecturers is predetermined.

- The preferred timeslots for each lecturer are predetermined, and they are sorted based on their priority.

- The preferred courses for each lecturer are predetermined, and they are sorted based on their priority.

Besides these assumptions, there are hard constraints that must be followed. These hard constraints are as the followings

- A class must be handled by a lecturer that is competent to deliver the related course.

- A class cannot be conducted outside its timeslot.

- A class cannot be conducted outside the allocated timeslots.

- A class is handled by only a lecturer [9].

- A lecturer cannot teach outside their preferred courses.

- A lecturer cannot teach outside their preferred timeslots.

- The lecturer cannot teach more than one class in a one-time slot. [6]

- The lecturer's preferred timeslots must be within the provided timeslots.
- The lecturer's preferred courses must be within the provided courses.

Annotations used in this mathematical model are as follow.

$\begin{array}{ll}c & \text { Class } \\ C & \text { set of classes } \\ f_{\text {totc }} & \text { total preferred courses } \\ f_{\text {tott }} & \text { total preferred timeslots } \\ g & \text { overall goal / objective } \\ l & \text { lecturer } \\ l_{s e l} & \text { selected lecturer } \\ L_{a v i} & \text { set of available lecturers } \\ L & \text { set of lecturers } \\ n_{u c} & \text { number of unserved classes } \\ o & \text { Course } \\ O & \text { set of courses } \\ O_{p r} & \text { set of preferred courses } \\ s_{e} & \text { status of a class }(0=\text { unserved, } 1=\text { served }) \\ s_{o} & \text { lecturer-class availability status based on } \\ & \text { course }(0=\text { unavailable, } 1=\text { available }) \\ s_{t} & \text { lecturer-class availability status based on } \\ & \text { timeslot }(0=\text { unavailable, } 1=\text { available) } \\ t & \text { timeslot } \\ T & \text { set of timeslots } \\ T_{p r} & \text { set of preferred timeslots } \\ v_{c o} & \text { course score of course } o \text { related to lecturer } l \\ v_{l t} & \text { lecturer-timeslot score of lecturer } l \text { that } \\ & \text { teaches class } c \\ v_{l c} & \text { lecturer-course score of lecturer } l \text { that } \\ & \text { teaches class } c\end{array}$

The objective of the proposed model is maximizing the total preferred courses, maximizing the entire preferred timeslots, and minimizing the number of unserved classes. This objective is formalized by using Eq. (1) to Eq. (7).

$$
\begin{gathered}
g=\max \left(f_{\text {totc }}+f_{\text {tott }}-n_{u c}\right) \\
f_{\text {totc }}=\sum_{n(c)} v_{l c}(l, c) \\
v_{l c}(l, c)=v_{c o}(l, o), l \in L \wedge l=l_{\text {sel }}(c) \\
f_{\text {tott }}=\sum_{n(c)} v_{l t}(l, c) \\
v_{l t}(l, c)=v_{t i}(l, t), l=l_{s e}(c) \wedge t(c)=t_{s e}(l, c) \\
n_{u c}=n\left(C_{u}\right) \\
C_{u}=\left\{c \mid c \in C \wedge s_{e}(c)=0\right\}
\end{gathered}
$$

Eq. (1) aims to maximize the three aspects: the total preferred courses, total preferred timeslots, and 
the negative value of the number of unserved classes. Eq. (2) states the total select course as the accumulation of the lecturer-course scores. Eq. (3) states that the lecturer-class scores of lecturer $l$ who teaches class $c$ are the preference score of the course taught by lecturer $l$ where this course is delivered in class $c$, and lecturer $l$ is the selected lecturer to teach class $c$. Eq. (4) states the total preferred timeslots is the accumulation of lecturer-timeslot score of lecturer $l$ to teach class $c$. Eq. (5) states that the lecturer-timeslots score of the lecturer $l$ to teach class $c$ as the timeslot score of timeslot $t$ relative to lecturer $l$, and lecturer $l$ is selected to teach class $c$. Eq. (6) states the number of unserved classes as the size of the set of the unserved classes. Eq. (7) defines the set of the unserved classes.

The lecturer selection to teach a class is determined randomly. It is determined by picking a class from a lecturers' pool. This pool consists of lecturers who is available to teach the class. Several aspects determine this availability. The first aspect is that this lecturer can lead the course delivered to this class. The second aspect is there is an available timeslot of this lecturer that is the same as the timeslot of the class. This selection mechanism is formalized by using Eqs. (8) to (12).

$$
\begin{gathered}
l_{\text {sel }}(c)=U\left(L_{\text {avi }}(c)\right) \\
L_{a v i}(c)=\left\{l \mid l \in L \wedge s_{o}(l, c)=1 \wedge s_{t}(l, c)=1\right\} \\
s_{o}(l, c)=\left\{\begin{array}{c}
1, \exists o_{p r}(l)=o(c) \\
0, \text { else }
\end{array}\right. \\
s_{t}(l, c)=\left\{\begin{array}{c}
1, \exists t_{a v}(l)=t(c) \\
0, \text { else }
\end{array}\right. \\
t_{a v}(l)=t_{p r}(l) \wedge s_{a v}(t, l)=1
\end{gathered}
$$

The explanation of Eqs. (8) to (12) is as follows. Eq. (8) states that the selected lecturer for class $c$ is determined from the available lecturer's pool, and it follows a uniform distribution. Eq. (9) states that the available lecturer pool consists of lecturers who handle class $c$ in both timeslot and course aspects. Eq. (10) states that lecturer $l$ is available to take class $c$ in the course aspect only if the course delivered in class $c$ is the lecturer $l$ 's preference. Eq. (11) states that lecturer $l$ can handle class $c$ in the timeslot aspect only if the lecturer l's available timeslot is the same as class $c$. Eq. (12) states that a timeslot is available for lecturer $l$ only if this timeslot is in the lecturer l's preferred timeslots and lecturer $l$ does not teach other classes at this timeslot.
This model is then optimized by the cloud theory-based simulated annealing (CTA), a derivative of the simulated annealing [15]. This CTA improves the basic simulated annealing (SA) method by transforming it into a population-based approach [15]. The CTA consists of a certain number of independent SA that runs independently. The idea is to provide several different solutions to have more opportunities to find better solutions. The final solution is chosen based on the individual who performs as the best solution or fitness value [15].

The CTA is chosen because of SA's characteristics, which focus on finding a global solution by avoiding local optimal traps [14]. This mechanism is obtained by a current solution that is worse than the best solution so far based on certain probabilistic parameters [14].

The improvement mechanism is conducted in every iteration during the SA process. In every iteration, a class is selected randomly. Then, this class is reallocated to other possible lecturers. This process is formalized by using algorithm 1 .

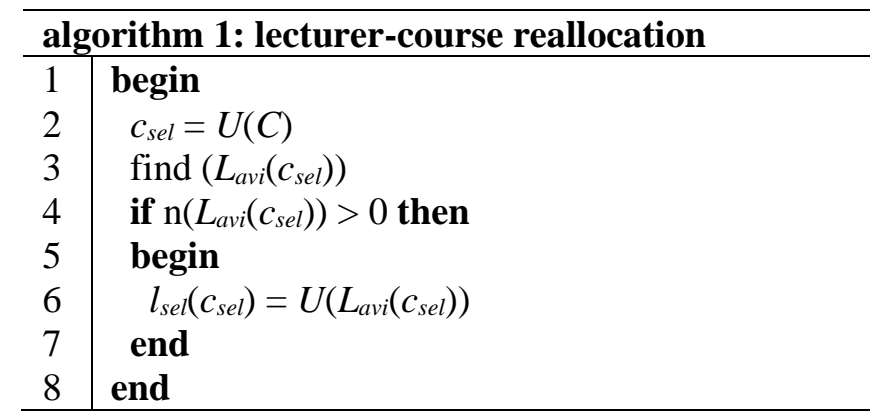

\section{Simulation and result}

This proposed model is then implemented into the lecturers-courses assignment simulation to evaluate its performance. In this simulation, the proposed model is compared with four previous lecturer-courses models. These models are chosen because they represent various objectives and circumstance in the lecturers-courses assignment problem. The first model was proposed by ArratiaMartinez, Maya-Padron, and Avila-Torres [13]. This model, shortened as AM. It represents model that its objective is to minimize the number of unserved courses without prioritizing the lecturer's capability and timeslot. Wicaksono and Wisesa [10] proposed the second model. It represents model that its objective is to maximize the lecturers' capability. This second model is acronymized as WW. The third model was proposed by Ongy [9]. This model is called as OY. It also represents model that its objective is to maximize the lecturer's competence score. Meanwhile, the lecturer's time preference is 
not considered. There is limitation in number of classes per course. In this simulation, we implement two scenarios for this limitation: one classes (OY-1) and two classes (OY-2) for the same courses. The fourth model was proposed by Gunawan and $\mathrm{Ng}$ [11]. Although this model is not new, it is important because it represents model that its objective is to balance the lecturers' load. It complements the other three latest existing models. It is acronymized as GN.

The simulation was conducted to observe the relationship between the number of lecturers and the observed parameters representing service quality. They are the total courses score, total timeslots score, and the number of unserved classes. There are also several static parameters, as shown in Table 2. The number of lecturers' preferred courses and timeslots is generated randomly, following the normal distribution. The lecturers' preferred timeslots and courses are generated randomly, and they follow a uniform distribution. The classes' timeslot and course are also generated randomly, and they follow a uniform distribution. Meanwhile, the number of lecturers ranges from 50 to 100 lecturers. Fig. 3, Fig. 4, and Fig. 5 show the lecturers total course score, total timeslot score, and total unserved class score, respectively.

Table 2. Static parameters

\begin{tabular}{|c|c|}
\hline Variable & Value \\
\hline$n(C)$ & 100 classes \\
\hline$n(\mathrm{O})$ & 10 courses \\
\hline$n(T)$ & 20 timeslots \\
\hline$n\left(T_{p r}\right)$ & 3 timeslots \\
\hline$n\left(O_{p r}\right)$ & 3 courses \\
\hline
\end{tabular}

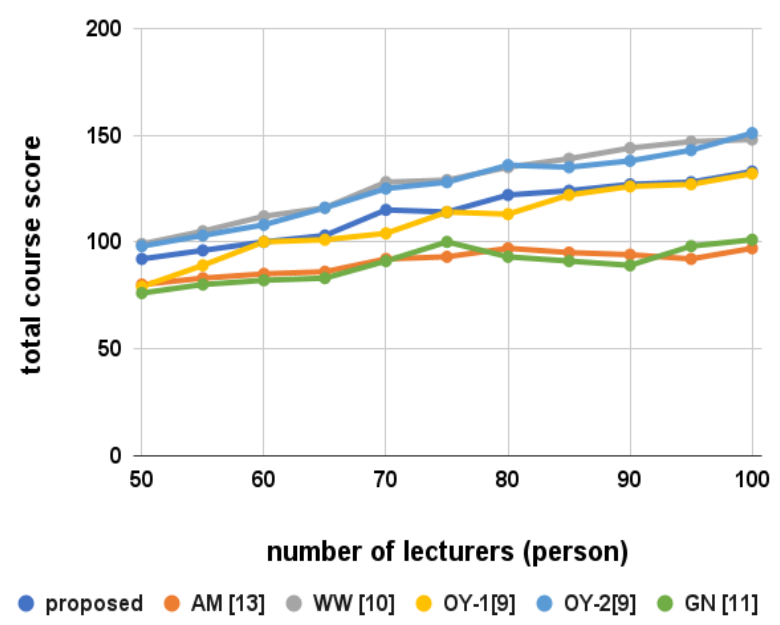

Figure. 3 Relation between number of lecturers and total course score
Fig. 3 shows that the total course number increases due to the increase in the number of lecturers. The total course score of the OY-2 [9] and the WW [10] increases significantly. Meanwhile, the increase of the total course score of the AM [13] and GN [9] is not significant. The WW [10] and OY-2 [9] perform as the best models in the total course score, while the AM model [13] and GN [11] perform as the worst models. The proposed model and OY-1 [9] perform moderately. When the number of lecturers is low (50 lecturers), the proposed model creates a $15 \%$ higher total course score than the AM model [13]. This value increases to $37 \%$ when the number of lecturers is high (100 lecturers).

Fig. 4 shows that the total timeslot score increments due to the increase in the number of lecturers. This condition happens in all models. Comparing among the models, the proposed model performs as the best model and outperforms the other models. Meanwhile, the total timeslot score of the previous models tends to be equal. Among the other models, the OY-1 [9] performs as the worst model in the total timeslot score aspect. When the number of lecturers is low (50 lecturers), the proposed model creates a $28 \%$ higher total timeslot score than the OY-1 [9]. This value decreases to $25 \%$ when the number of lecturers is high (100 lecturers).

Fig. 5 shows that the number of unserved classes decreases due to the number of lecturers. All the models show similar trends, and the gap between the models is very small. This result indicates that the increase of supply of lecturers will decrease the number of unserved classes. The AM [13] performs as the best model, while the OY-1 [9] performs as the worst. The proposed model performs moderately

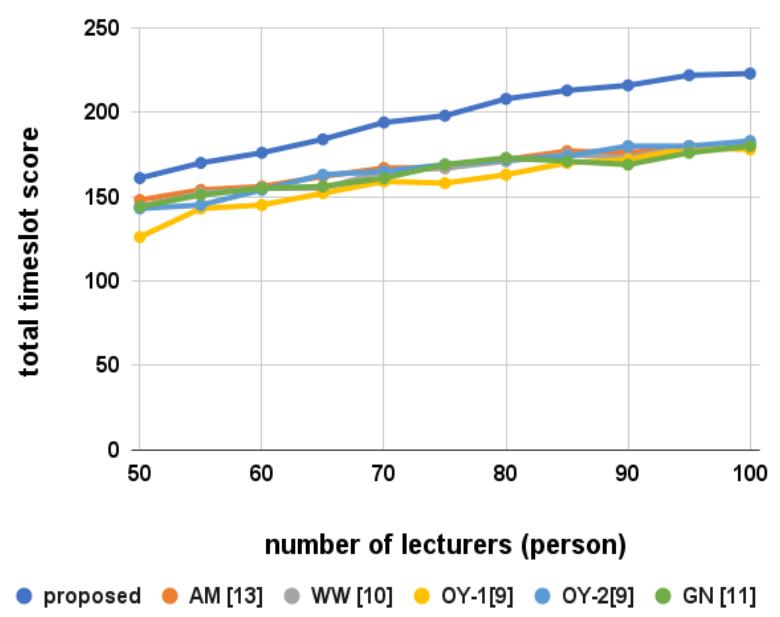

Figure. 4 Relation between number of lecturers and total timeslot score 


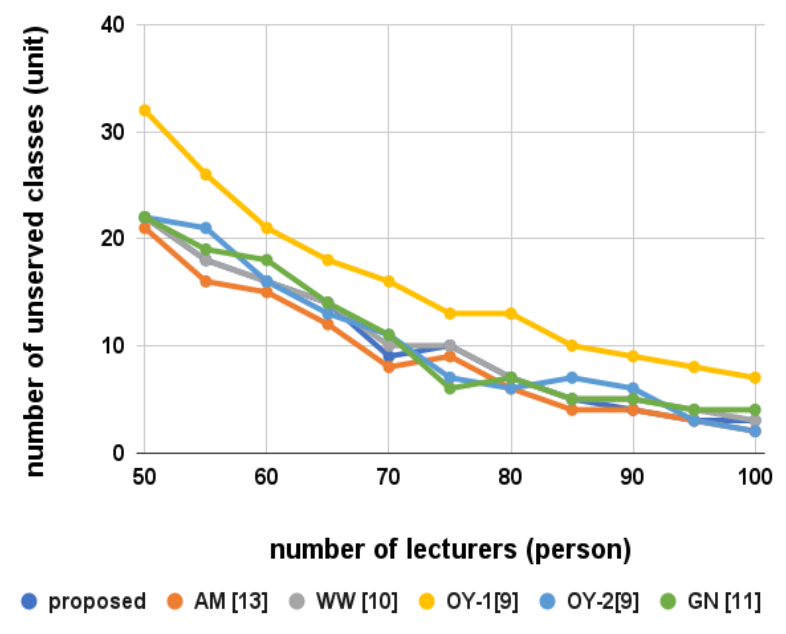

Figure. 5 Relation between number of lecturers and number of unserved classes

in between the previous two models. When the number of lecturers is low (50 lecturers), the proposed model creates a 5 percent higher number of unserved classes than the AM model [13]. This value stays the same when the number of lecturers is high (100 lecturers).

\section{Discussion}

In this section, the simulation result will be analysed deeper. It will relate to the research purpose and the theoretical aspect so that the findings can be explored. The analyses include comparing the proposed model and all previous models, the AM [13], WW [10], OY-1 [9], OY-2 [9], and GN [11] models.

Based on the result in Fig. 3 to Fig. 5, it is shown that the supply-demand balance affects all three observed parameters. The increase of the supply, when the demand is fixed, makes the service quality increases too. For instance, the unserved class decreases. On the other hand, the total course score and total timeslot score increase in all models.

The proposed model performs moderately among models in the total course score aspect. Meanwhile, the WW [10] and OY-2 [9] perform best, and the AM [13] and GN [11] performs worst. The reason is that the WW [10] and OY [9] prioritizes the course preference only. Meanwhile, the AM [13] and GN [9] do not concern with the lecturers' course preference. The OY-2 performs better than OY-1 because the OY-2 is more flexible rather than OY-1. The proposed model performs less than the WW because the proposed model involves more than the total course score aspect only.

The proposed model performs as the best model in the total timeslot score. The reason is that the proposed model is the only model, compared with other models, that also consider the timeslot preference aspect. This advantage improves the overall model due to the increasing of supply. It means the system with the proposed model will have more opportunities to allocate lectures to classes that are better in complying with the lecturers' preferred timeslots. This time slot preference aspect has been implemented in the fitness calculation.

\section{Conclusion}

In this research, a new lecturers-courses assignment model that suits the national joint courses program has been demonstrated. The proposed model includes the timeslot window and course relevance aspects in its fitness function, fulfilling the research objective. By comparing with the four previous lecturers-courses models, the proposed model performs as the best model in creating a high total timeslot score and moderate model in creating a high total course and number of unserved classes. The proposed model makes a $15 \%$ to $37 \%$ higher total course score than the previous model that does not prioritize course preference. The proposed model also produces a $25 \%$ to $28 \%$ higher total timeslot score than other previous models.

This work is developed based on several limitations. The course and timeslot preferences are abstracted in a single score each. These preferences are constructed from several parameters. For example, a course preference score is built from the lecturer's expertise and teaching experience. Each timeslot preference is also generalized equally. For example, class is better conducted in the morning rather than in the afternoon. These aspects can be used as the basis for improving this work in the future.

\section{Conflicts of Interest}

The authors declare no conflict of interest.

\section{Author Contributions}

Conceptualization: Kusuma; methodology: Kusuma; software: Kusuma; validation: Kusuma; formal analysis: Kusuma and Adiputra; investigation: Kusuma; writing-original draft preparation: Kusuma; writing-review and editing: Adiputra.

\section{Acknowledgments}

This work is funded and supported by Telkom University, Indonesia. 


\section{References}

[1] S. Pokhrel and R. Chhetri, "A Literature Review on Impact of COVID-19 Pandemic on Teaching and Learning", Higher Education for the Future, Vol. 8, No. 1, pp. 133-141, 2021.

[2] S. Dhawan, "Online Learning: A Panacea in the Time of COVID-19 Crisis", Journal of Educational Technology Systems, Vol. 49, No. 1, pp. 5-22, 2020.

[3] M. M. Zalat, M. S. Hamed, and S. A. Bolbol, "The Experiences, Challenges, and Acceptance of E-learning as a Tool for Teaching during the COVID-19 Pandemic among University Medical Staff", PloS ONE, Vol. 16, No. 3, pp. 1-12, 2021.

[4] D. Hermawan, "The Rise of E-learning in COVID-19 Pandemic in Private University: Challenges and Opportunities", International Journal of Recent Educational Research, Vol. 2, No. 1, pp. 86-95, 2021.

[5] K. Zhu, D. Li, and M. Li, "A Survey of Computational Intelligence in Educational Timetabling", International Journal of Machine Learning and Computing, Vol. 11, No. 1, pp. 40-47, 2021.

[6] M. Assi, B. Halawi, and R. A. Haraty, "Genetic Algorithm Analysis using the Graph Coloring Method for Solving the University Timetable Problem", Procedia Computer Science, Vol. 126, pp. 899-906, 2018.

[7] I. Balan, "A New Genetic Approach for Course Timetabling Problem", Journal of Applied Computer Science \& Mathematics, Vol. 15, No. 1, pp. 9-14, 2021.

[8] S. T. Ngo, J. Jaafar, I. A. Aziz, and B. N. Anh, "A Compromise Programming for MultiObjective Task Assignment Problem", Computers, Vol. 10, pp. 1-16, 2021.

[9] E. E. Ongy, "Optimizing Student Learning: A Faculty-Course Assignment Problem Using Linear Programming", Journal of Science, Engineering and Technology, Vol. 5, pp. 1-14, 2017.

[10] I. E. Wicaksono and W. W. Wisesa, "An Optimization Model for Teaching Assignment based on Lecturer's Capability Using Linear Programming", Indonesian Journal of Artificial Intelligence and Data Mining, Vol. 3, No. 2, pp. 57-63, 2020.

[11] A. Gunawan and K. M. Ng, "Solving the Teacher Assignment Problem by Two Metaheuristics", International Journal of Information and Management Sciences, Vol. 22, pp. 73-86, 2011.
[12] S. Faudzi, S. A. Rahman, and R. A. Rahman, "An Assignment Problems and Its Application in Education Domain: A Review and Potential Path", Advances in Operations Research, pp. 119, 2018.

[13] N. M. A. Martinez, C. M. Padron, and P. A. A. Torres, "University Course Timetabling Problem with Professor Assignment", Mathematical Problems in Engineering, pp. 1-9, 2021.

[14] A. P. Engelbrecht, Computational Intelligence: An Introduction, $2^{\text {nd }}$ ed. Wiley, 2007.

[15] C. L. Hsu, W. C. Lin, L. Duan, J. R. Liao, C. C. $\mathrm{Wu}$, and J. H. Chen, "A Robust Two-machine Flow-shop Scheduling Model with Scenariodependent Processing Times", Discrete Dynamics in Nature and Society, pp. 1-16, 2020.

[16] C. Mallick, S. K. Bhoi, K. K. Jena, K. S. Sahoo, M. Humayn, and M. H. Shahd, "CLAPS: Course and Lecture Assignment Problem Solver for Educational Institution Using Hungarian Method", Turkish Journal of Computer and Mathematics Education, Vol. 12, No. 10, pp. 3085-3092, 2021.

[17] D. S. Dinagar and B. C. Raj, "Stephen's Algorithm for Solving Assignment Problems", Advances and Applications in Mathematical Sciences, Vol. 20, No. 5, pp. 887-894, 2021.

[18] H. G. Wieloch, "The Assignment Problem in Human Resource Project Management under Uncertainty", Risks, Vol. 9, pp. 1-18, 2021.

[19] S. Supian, S. Wahyuni, J. Nahar, and Subianto, "Optimization of Personnel Assignment Problem Based on Traveling Time by Using Hungarian Methods: Case Study on the Central Post Office Bandung", IOP Conference Series: Material Science and Engineering, Vol. 300, pp. 1-6, 2018. 